\title{
PREDICTION OF INFLOW TO THE UJJANI DAM RESERVOIR USING LINEAR REGRESSION AND HYBRID MODEL
}

\author{
Dattatray Rajmane
}

Research Scholar, Department of Civil Engineering, SGGSI \&T - Shri Guru Gobind Singhji Institute of Engineering \& Technology, Nanded, Maharashtra, India.

\section{Milind Waikar}

Professor, SGGSI \&T - Shri Guru Gobind Singhji Institute of Engineering \& Technology, Nanded, Maharashtra, India.

\begin{abstract}
Assessment of impact of climate change is very essential for the areas where the water scarcity is the main issue. Ujjani dam one of the largest dams of Maharashtra state in India is constructed on Bhima river in 1980 which supplies water to downstream culturable area of Solapur and Pune district. In this study statistical downscaling model was developed for downscaling and projecting the temperature and rainfall by considering the GFDL-CM3 (GCM) model under scenario RCP 6.0. Statistical downscaling models showed a very good correlation (R2) between NCEP predictors and hydro metrological predictands. Using the projected values of temperature and rainfall, inflow to the reservoir was predicted by developing the three different models namely, multiple linear regression, Artificial neural network and Wavelet neural network. The models were evaluated by using mean square error criteria. It is observed that there is a change in rainfall pattern, it increases in the months of September to December however it decreases in the months of June to August, this is due to corresponding changes in rainfall. The inflow to the reservoir has been predicted in three different time period viz 2020-29, 2050-59 and 2080-89.
\end{abstract}

Keywords: Statistical Downscaling, Multiple linear regression, Artificial Neural network, Wavelet neural network, Ujjani Dam

Cite this Article: Dattatray Rajmane and Milind Waikar, Prediction of Inflow to the Ujjani Dam Reservoir using Linear Regression and Hybrid Model, International Journal of Civil Engineering and Technology, 11(12), 2020, pp. 39-46.

https://iaeme.com/Home/issue/IJCIET?Volume=11\&Issue $=12$ 


\section{INTRODUCTION}

The period from 1983 to 2012 was likely the warmest 30-year period of the last 1400 years in the Northern hemisphere. The globally averaged combined land and ocean surface temperature data show a warming of $0.70 \mathrm{C}$ over the period of 1900 to 2000 [1]. Many studies identified that due to rise in temperature, changes have been in observed in rainfall and stream flow quantity and pattern. Climate change will cause change in temperature, precipitation pattern and other climate variables [2]. The areas under semiarid and arid regions where the survival of people is totally dependent on rainfall, it is very essential to study the effect of climate change over these hydrological parameters. In this study, the effect of climate change to the inflow of Ujjani dam reservoir is evaluated. Ujjani dam reservoir supplies water to downstream area of Solapur district in Maharashtra in India where the average annual rainfall is very less about $50 \mathrm{~cm}$ and temperature goes to $480 \mathrm{C}$ in the month of April. The objective of the study is to assess the change in monthly inflow to the reservoir due to climate change. To project the temperature and precipitation downscaling methodology has been used. Multiple linear regression (MLR) and artificial neural network (ANN) models has been developed using hydro metrological data. Relationship between predict and (rainfall, temperature) and predictors (atmospherically variables) was established using MLR and ANN techniques. Developed models have been used for projection of temperature and precipitation using General Circulation Model (GCM) variables. These projected temperature and precipitation were used for prediction of probable inflow to the reservoir. Prediction of inflow was done by using three types of models namely, MLR, ANN and Wavelet neural network (WNN). The model which shows better evaluation performance has been used to assess the change in monthly inflow to the reservoir. The results were analyzed for three different future time periods viz 2020-29, 2050-59 and 2080-89.

\section{STUDY AREA AND DATA ANALYSIS}

\subsection{Study Area}

Ujjani dam built across Bhima river in 1980 in Solapur district of Maharashtra. It is an earth cum gravity dam. It's height above the lowest foundation is about $56.40 \mathrm{~m}$ and $2540 \mathrm{~m}$ long. Its gross storage capacity is $3320 \mathrm{~km} 3$ and reservoir surface area is $290 \mathrm{~km} 2$. effective storage capacity is $1520 \mathrm{~km} 3$. it is multipurpose dam constructed for irrigation, water supply and hydroelectric power generation. It's designed spillway capacity is about $18010 \mathrm{~m} 3 / \mathrm{s}$ [3]. The basin area on upstream side of Ujjani dam is called as Upper Bhima basin. Upper Bhima basin shown in fig. 1 is located within the coordinates of $17.18 \mathrm{~N}$ to $19.24 \mathrm{~N}$ latitude and 73.20E to $76.15 \mathrm{E}$ longitude.

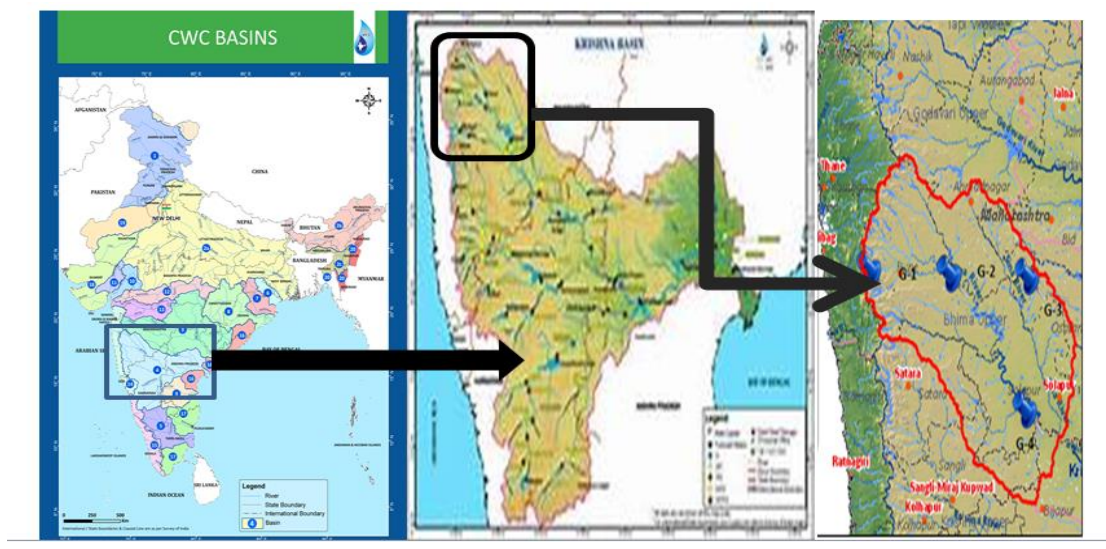

Figure 1. Basin map of India, Krishna Basin, and Upper Bhima basin (Source: India WRIS, http://www.indiawris.gov.in) 
Table 1 Station Points for Upper Bhima basin

\begin{tabular}{|c|l|l|l|}
\hline Station & \multicolumn{1}{|c|}{ Latitude-Longitude } & \multicolumn{1}{c|}{ Place } & \multicolumn{1}{c|}{ State } \\
\hline 1 & $17.25 \mathrm{~N}-75.25 \mathrm{E}$ & Tembhurni & Maharashtra \\
\hline 2 & $18.25 \mathrm{~N}-73.25 \mathrm{E}$ & Mulshi & Maharashtra \\
\hline 3 & $18.25 \mathrm{~N}-74.25 \mathrm{E}$ & Supa & Maharashtra \\
\hline 4 & $18.25 \mathrm{~N}-75.25 \mathrm{E}$ & Kashti Ghod & Maharashtra \\
\hline
\end{tabular}

\subsection{Data Collection: Three types of data have been used for this study}

\subsubsection{Observed Temperature and Precipitation Data}

Observed temperature and rainfall (Predictands) data has been collected from Indian Metrology Department, Pune. It is available at $10 \times 10$ grid. Data of four grid stations as mentioned in Table1 lying within the Upper Bhima basin has been acquired. Data has been collected from Jan 1969 to Dec. 2015 period.

\subsubsection{National Centre for Environmental Protection (NCEP) Data}

NCEP data (Predictors for Training) is basically the data of observed atmospheric variables. Spatial resolution of this data is about $2.50 \times 2.50$. This data is downloaded from site https://sdsm.org.uk on daily basis then it is converted in average monthly scale.

\subsubsection{Global Climate Model Data}

GCM (Predictors for Forecasting) data for GFDL-CM3 model was downloaded from https://esgf-node.llnl.gov web site on monthly basis considering RCP 6.0 scenario. It is available in. netcdf format, can be made in readable form by using ArcGIS, MATLAB or Panoply software.

\subsubsection{Inflow Data}

Monthly inflow to the Ujjani reservoir in Mm3 from 1981 to 2015 has been collected from water resources department, Govt. of Maharashtra.

\subsection{Data Processing}

It is required to process the large-scale climate variables downloaded data before using it for model calibration.

\subsubsection{Interpolation}

NCEP data is available at $2.50 \times 2.50$ and GCM data is available at $20 \times 2.50$ resolution. IMD data resolution is $10 \times 10$. Hence NCEP and GCM data are required to interpolate at the grid size of $10 \times 10$ to match the coordinates of four station points. Interpolation can be carried out by using MATLAB.

\subsubsection{Standardization}

Standardization means rescaling the data to have mean value zero and standard deviation equal to one. It is the process of converting disparate dataset into common dataset format which gives consistent data form. Standardization is conventional method to remove the bias in GCM output data set [4].

$$
\text { Standardized Value }=\frac{(\text { Original Value }- \text { Mean })}{\text { Standard Deviation }}
$$




\section{METHODOLOGY}

\subsection{Statistical Downscaling of Temperature and Rainfall and its Prediction}

Statistical downscaling has been carried out by using MLR and ANN techniques for the Upper Bhima basin considering four stations within it [5]. It has been observed that ANN based downscaling technique was outperformed the MLR by considering the coefficient of Determination as an evaluation criterion. The coefficient of correlation $\mathrm{R}^{2}$ value in Table 2 shows a strong correlation between observed and simulated values [6]. $\mathrm{R}^{2}$ value less than 0.35 represents weak correlation, between 0.36 to 0.67 represents moderate correlation and greater than 0.67 to 1 represents strong correlation [7,8]. Owing to its better performance the ANN technique has been used to predict temperature and rainfall using GFDL-CM3 (GCM) in the Upper Bhima basin up to the year 2100in three different time frames viz 2020-29,2050-59 and 2080-89 at all four grids. In this study RCP 6.0 scenario is considered. RCP 6.0 stand for Representative Concentration Pathway and $6.0 \mathrm{~W} / \mathrm{m} 2$ will be radiative forcing in the year 2100 relative to 1750 [9].

\subsection{Development of Rainfall-Runoff Model}

Rainfall runoff model was developed using MLR, ANN and Wavelet Neural Network (WNN). The inputs to the model were considered as temperature and rainfall at four stations within Upper Bhima basin. The training and testing of the model were carried out by using historical data of temperature, rainfall and runoff at gauging station. The model was evaluated using mean square error criteria. The model which gives least mean square error was selected for prediction of inflow to the reservoir .

\subsubsection{Multiple Linear Regression (MLR)}

Regression analysis is very useful for forecasting. In MLR, dependent variable (Predictand) is one and independent variables (Predictors) are more than one. The basic model is designed between dependent and independent variables by using least square method. A relation between dependent and independent variables is linear. Once the model is developed, it will be used for forecasting of predictand value corresponding the predictors values from GCM outputs.

Table 2 Comparison of $\mathrm{R}^{2}$ Value

\begin{tabular}{|c|c|c|c|c|c|c|c|c|c|}
\hline \multirow[t]{5}{*}{ MLR } & Climate & \multicolumn{4}{|c|}{ CALIBRATION } & \multicolumn{4}{|c|}{ VALIDATION } \\
\hline & & $\begin{array}{c}\text { Station } \\
1\end{array}$ & $\begin{array}{c}\text { Station } \\
2 \\
\end{array}$ & $\begin{array}{c}\text { Station } \\
\mathbf{3}\end{array}$ & $\begin{array}{c}\text { Station } \\
4\end{array}$ & $\begin{array}{c}\text { Station } \\
1\end{array}$ & $\begin{array}{c}\text { Station } \\
2 \\
\end{array}$ & $\begin{array}{c}\text { Station } \\
\mathbf{3}\end{array}$ & $\begin{array}{c}\text { Station } \\
4\end{array}$ \\
\hline & Tmax & 0.932 & 0.948 & 0.947 & 0.956 & 0.938 & 0.929 & 0.947 & 0.938 \\
\hline & Tmin & 0.953 & 0.973 & 0.946 & 0.958 & 0.941 & 0.962 & 0.969 & 0.937 \\
\hline & Rainfall & 0.894 & 0.5 & 0.5 & 0.51 & 0.887 & 0.09 & 0.53 & 0.13 \\
\hline \multirow{5}{*}{ ANN } & & \multicolumn{4}{|c|}{ CALIBRATION } & \multicolumn{4}{|c|}{ VALIDATION } \\
\hline & & $\begin{array}{c}\text { Station } \\
1\end{array}$ & $\begin{array}{l}\text { Station } \\
2\end{array}$ & $\begin{array}{c}\text { Station } \\
\mathbf{3}\end{array}$ & $\begin{array}{c}\text { Station } \\
4\end{array}$ & $\begin{array}{c}\text { Station } \\
1\end{array}$ & $\begin{array}{c}\text { Station } \\
2\end{array}$ & $\begin{array}{c}\text { Station } \\
\mathbf{3}\end{array}$ & $\begin{array}{c}\text { Station } \\
4\end{array}$ \\
\hline & Tmax & 0.977 & 0.982 & 0.977 & 0.982 & 0.957 & 0.946 & 0.938 & 0.946 \\
\hline & Tmin & 0.981 & 0.989 & 0.979 & 0.985 & 0.938 & 0.967 & 0.966 & 0.936 \\
\hline & Rainfall & 0.954 & 0.849 & 0.815 & 0.888 & 0.878 & 0.5 & 0.67 & 0.606 \\
\hline
\end{tabular}




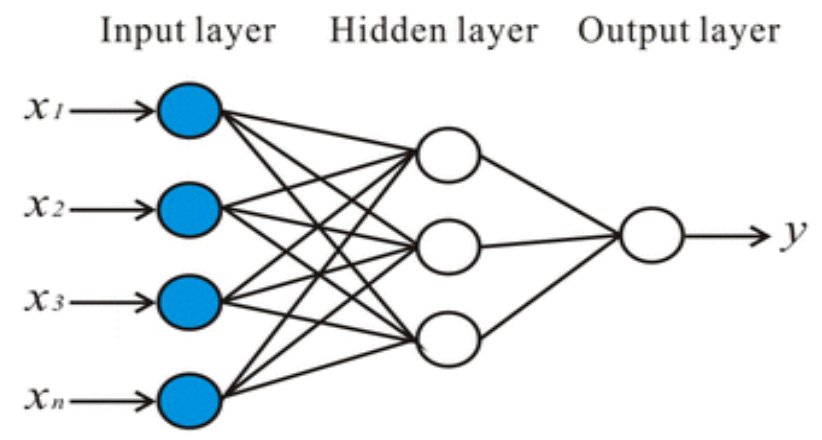

Figure 2 Feed forward back propagation neural network

\subsubsection{Artificial Neural Network (ANN)}

ANN has been developed as a generalization of mathematical models of human cognition or neural biology [10]. It is a network consists of nodes which are linked to each other by layer to layer. In typical neural network as shown in fig.2 [11], first layer is input layer and final layer is output layer. There can be one or more hidden layers consisting of one or more nodes. Each node is connected to the nodes in previous layer and next layer through links. Rumlhart (1986), rediscovered a backpropagation algorithm by which an error is propagated backward in the network through links and correspondingly the connection weights and bias values are adjusted [12].

\subsubsection{Wavelet Neural Network (WNN)}

Wavelet Neural Network is a hybridization of wavelet transformation and artificial neural network. Wavelet is a small wave. wavelet transformation has advantage over Fourier transform. WNN can decompose stationary as well as no stationary data which gives information about frequency and time domain with high resolution where as traditional Fourier transform can be used for decomposition of stationary data. Sines and cosine waves are big waves [13]. A wavelet function $\psi(\mathrm{t})$ can be defined as

$$
\int_{-\infty}^{\infty} \psi(t) d t=0
$$

Some wavelet families are Harr wavelet which is oldest and simplest wavelet, Daubechies wavelet, Coiflet wavelet etc. In WNN model the discrete wavelet transformation discretizes the input data (rainfall and temperature) inti number of sub signals in the form of approximations and details. These discretized data have been used as input to ANN as shown in figure 3 and with runoff as output data model has been trained. Performance of the model was evaluated using mean square error criteria. Monthly average discharge was determined from the available data of inflow at Daund station from 1981 to 2015. Initial 25 years data was used for training and remaining 10 years data was used for testing of each model and results are obtained.

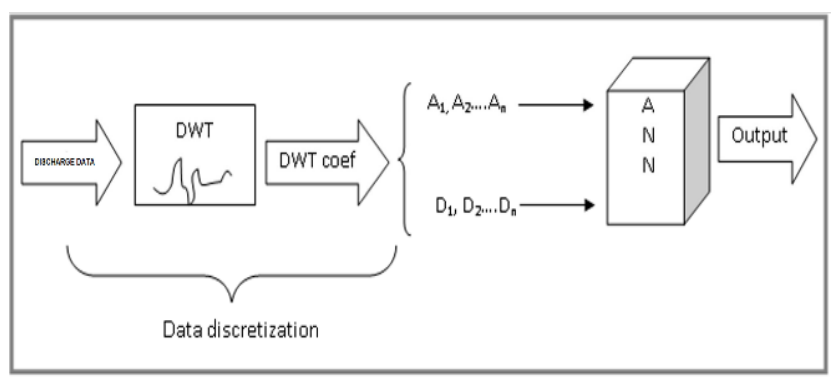

Figure 3 Wavelet Neural Network Structure 


\section{RESULTS AND DISCUSSIONS}

Results were obtained from the calibration of the three models namely MLR, ANN and WNN. The projected rainfall and temperature were used as input to the calibrated and tested MLR model. The future probable values of inflow were predicted by simulation of the model. From the simulated results, the mean square value was obtained. Similarly, the inflows are predicted by using optimal ANN model using the inputs as the projected temperature and rainfall from 2006-2100. In WNN model, discrete wavelet transformation was used with various types of wavelets such as Daubechies wavelet of order 4 (DB4), Coiflet-2 and Symhlet-4 wavelet selected as mother wavelet considering the similarity with the time series signals $[14,15]$. The effects of various decomposition levels on model efficiency have in the form of approximations and also investigated to optimize the result. The optimum result from the discrete wavelet transformation and detail sub signals at different levels presented in figure 4 .

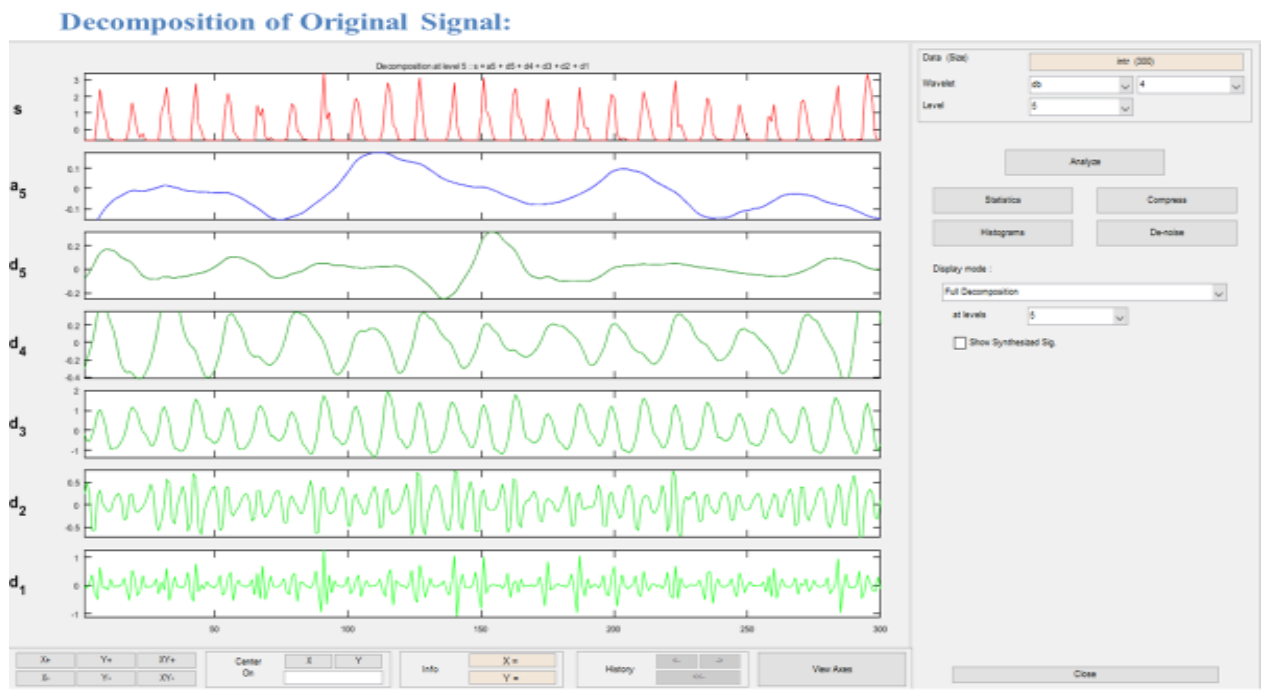

Figure 4 Decomposition of Original Signal using DB-4 Wavelet

The inflow to the reservoir using the three models was compared with the observed values for the period 2006-2015. It is seen from figure 5 that MLR model is giving comparatively closure results with the observed values and mean square error by the MLR model was shown in Table 3 lesser as compared to ANN and WNN model. Therefore, MLR model has been used for the prediction of inflow from 2006 to 2100.

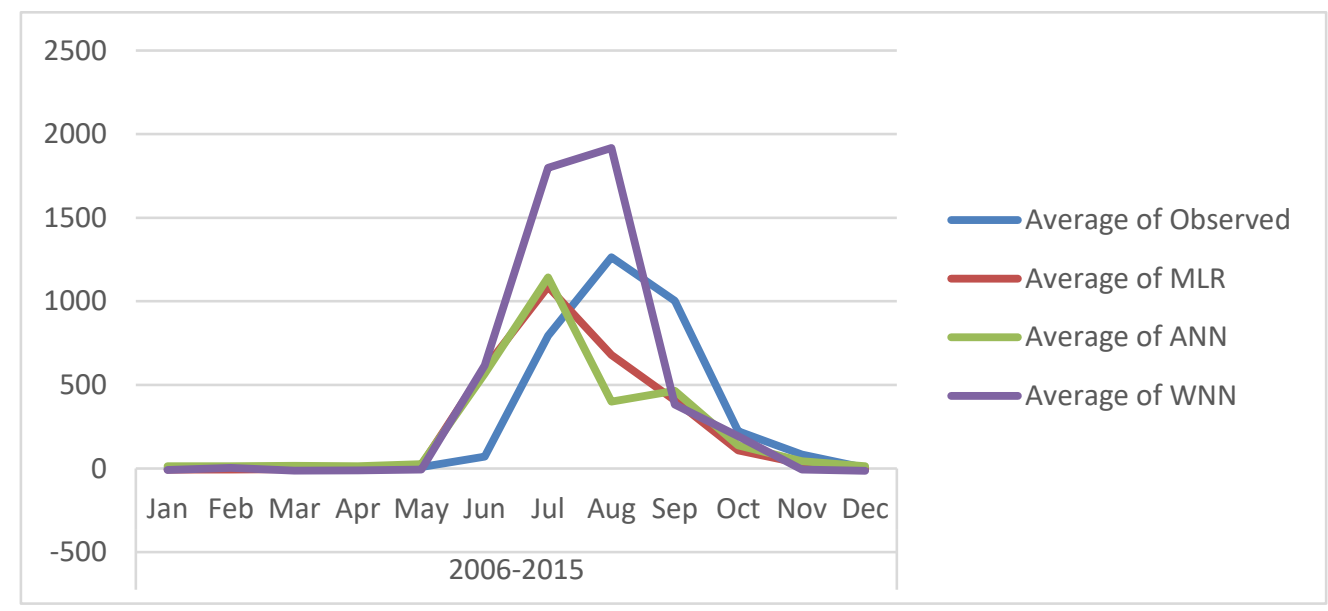

Figure 5 Comparison of Observed Inflow by MLR, ANN and WNN 
Table 3 Comparison of Mean Square Error

\begin{tabular}{|c|c|c|}
\hline \multicolumn{3}{|c|}{ Mean Square Error (MSE) Value for Inflow } \\
\hline MLR (x10^6) & ANN $\left(\times 10^{\wedge} 6\right)$ & WNN $\left(\times 10^{\wedge} 6\right)$ \\
\hline 0.34 & 0.419 & 0.482 \\
\hline
\end{tabular}

The projected rainfall and temperature were used for the prediction of inflow to the reservoir. The results are presented in graphical form in figure 6 for the different periods of 2020-29, 2050-59 and 2080-89.

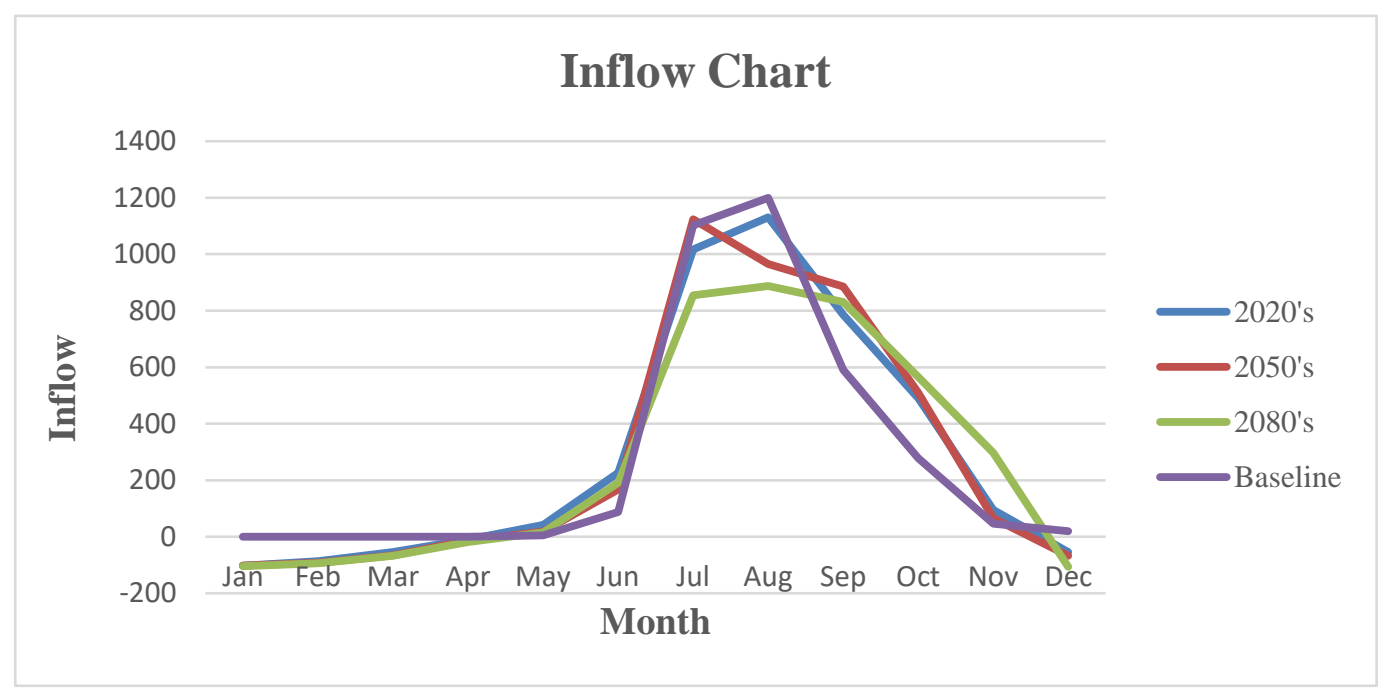

Figure 6 Probable future Inflow

\section{CONCLUSION}

In this study, using the multiple linear regression and artificial neural network based statistical downscaling technique, the future rainfall and temperature over Upper Bhima basin has been predicted from 2006 to 2100 for three different time periods viz 2020-2029, 2050-59 and 2080-89. Decrease in rainfall from June to August has been observed however there is an increase in rainfall in the months of September to December. Using this predicted temperature and rainfall as input, inflow to the reservoir has been simulated using MLR, ANN and WNN models for three different time periods. Increase in runoff has been observed in September to December, this is because of increase in rainfall have direct impact on runoff. MLR showed better performance according to MSE criteria. These observed changes in inflow pattern have to be considered in reservoir operation schedule. In projection of rainfall and temperature ANN based model performing better than MLR model, this is because of nonlinear relation between predictors and predict and. However, in prediction of reservoir inflow out of three models namely MLR, ANN and WNN, it has been observed that MLR outperformed the other two models. Hence it shows that for prediction of variable use of model depends on the nature of data, any particular model is not suit for the all forecasting results.

\section{REFERENCES}

[1] IPCC Report 2014.

[2] Changchun, X., Yaning, C. and Weihong, L. (2008). Potential impact of climate change on snow cover area in the Tarim River basin. Environ. Geol., 53, pp. 1465-1474 
[4] Subimal Ghosh, P.P. Mujumdar, "Statistical Downscaling of GCM simulations to streamflow using relevance vector machine", Advances in Water Resources, Vol 31, July 2007, pp. 132146

[5] E.P. Salathe, Jr., P.W. Mote and M.W. Wiley, "Review of scenario selection and downscaling methods for the assessment of climate change impacts on hydrology in the United States Pacific Northwest", Int. J. Climatol., Vol. 27, (2007), 1611-1621.

[6] D.K. Rajmane and M.L. Waikar, "Projection of Temperature and precipitation using multiple linear regression and artificial neural network as downscaling methodology for Upper Bhima basin”, Int. J. Recent Technology and Engineering, Vol.9, sept. 2020.

[7] Weber, J.C., and Lamb, D.R. (1970). Statistics and research in physical education. St. Louis: CV Mosby Co, 222, pp: 59-64.

[8] Mason, R.O., Lind, D.A., and Marchal, W.G. (1983). Statistics: An introduction. New York: Harcourt Brace Jovanovich, Inc, 368-383.

[9] B. C. Hewitson and R.G. Crane, "Climate downscaling: techniques and application", Clim. Res., vol.7, (1996), 85-95.

[10] Rao S. Govindaraju, "Artificial neural network in hydrology I: Preliminary concepts”, Journal of Hydrologic Engineering, Vol. 5, April 2000, 115-123

[11] Ahmed Amara Konate Heping Pan, Nasir Khan and Jie Huai Yang, "Generalized regression and feed forward back propagation neural network in modelling porosity from Geophysical well logs", Journal of Petroleum exploration and production Technology, Vol.5, (2015), 157166.

[12] David E. Rumelhart, Geoffrey E. Hintont \& Ronald J. WilliamsJ. Wang, "Learning representations by back-propagating errors", Nature Publishing Group, Vol.323 (9), 1986, pp 533-536.

[13] Percival, D.B and Walden, A.T.2000. "Wavelet methods for time series analysis". Cambridge University Press, Cambridge.

[14] Daubechies, I., 1992. "Ten lectures on wavelets. Society for Industrial and Applied Mathematics", Philadelphia, PA.

[15] Mallat S G.1998. “A wavelet tour of signal processing” Academic, San Diego. 